\title{
Shoes that restrict metatarsophalangeal dorsiflexion cause proximal joint compensations
}

\author{
Dominic Thewlis ${ }^{1,2^{*}}$, Gunther Paul ${ }^{3}$, Chris Bishop ${ }^{1}$ \\ From 3rd Congress of the International Foot and Ankle Biomechanics Community \\ Sydney, Australia. 11-13 April 2012
}

\section{Study aim}

To describe barefoot, shod and in-shoe kinematics during stance phase of walking gait in a normal arched adult population.

\section{Materials and methods}

An equal sample of males and females $(n=24)$ was recruited. In order to quantify the effect of footwear independent of technical design features, an ASICS shoe (Onitsuka Tiger-Mexico 66, Japan) was used in this study. Markers were applied to three conditions; barefoot, shod, and in-shoe. The calibration markers were used to define static pose. The order of testing was randomised. Partici- pants completed five trials in each condition. Kinematic data were captured using a 12 camera VICON MX40 motion capture system at $100 \mathrm{~Hz}$ and processed in Visual3D. A previously developed model was used to describe joint angles [1]. A univariate two-way ANOVA was used to identify any differences between the pairs of conditions. Post-hoc Sheffé tests were used to further interrogate the data for differences.

\section{Results}

At peak hallux dorsiflexion (Figure 1), during propulsion, the metatarsophalangeal joint (MPTJ) was significantly more dorsiflexed in the barefoot condition

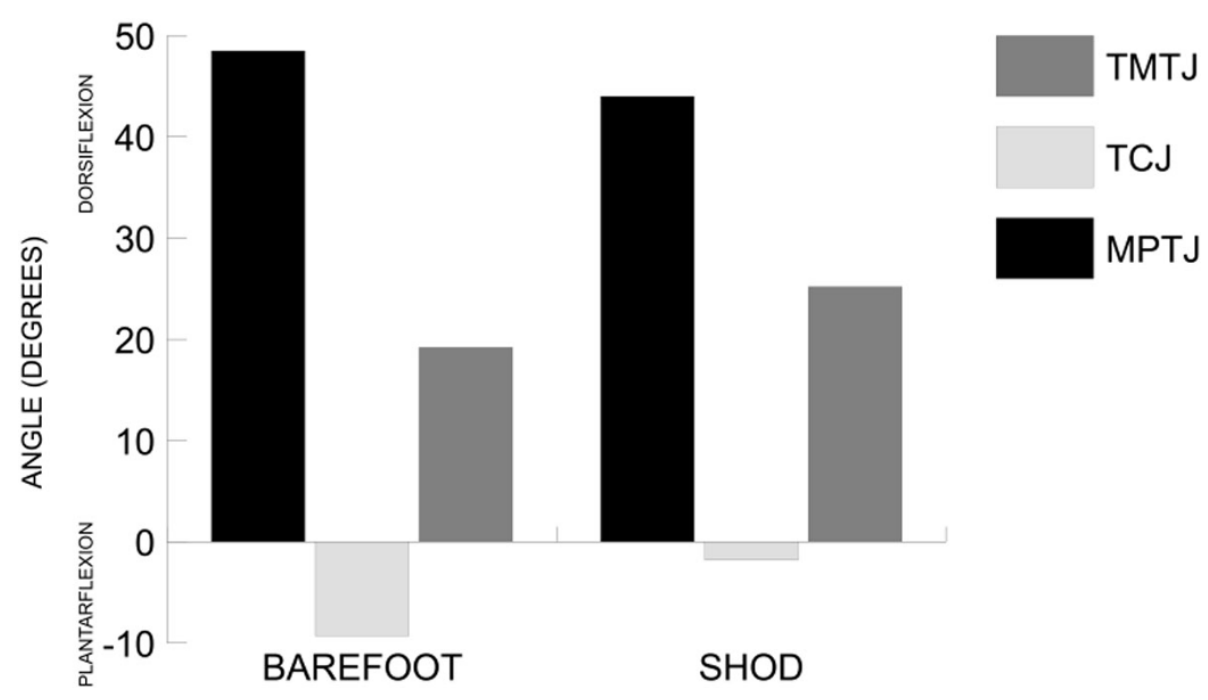

Figure 1 Joint angles (degrees) at peak hallux dorsiflexion

\footnotetext{
* Correspondence: dominic.thewlis@unisa.edu.au

${ }^{1}$ School of Health Sciences, University of South Australia, Adelaide, South

Australia, 5000, Australia

Full list of author information is available at the end of the article
}

(c) 2012 Thewlis et al; licensee BioMed Central Ltd. This is an Open Access article distributed under the terms of the Creative Commons 
compared to the shod condition $(p=0.004)$. At the same gait event, the tibiocalcaneal joint (TCJ) was significantly more plantarflexed than both the shod and inshoe conditions $(p<0.001)$, and the tarsometatarsal joint (TMTJ) was significantly less dorsiflexed in the barefoot condition compared to the shod and in-shoe conditions $(p<0.001)$.

\section{Conclusions}

The findings of the current study demonstrate that footwear has significant effects on sagittal plane MPTJ joint dorsiflexion at peak hallux dorsiflexion, which results in compensations at proximal foot joints.

\section{Acknowledgements}

ASICS Oceania provided the footwear for the study.

\section{Author details}

${ }^{1}$ School of Health Sciences, University of South Australia, Adelaide, South Australia, 5000, Australia. ${ }^{2}$ Sansom Institute for Health Research, University of South Australia, Adelaide, South Australia, 5000, Australia. ${ }^{3}$ Mawson Intitute,

University of South Australia, Adelaide, South Australia, 5041, Australia.

Published: 10 April 2012

\section{Reference}

1. Bishop C, et al: The development of a multi-segment kinematic model of footwear. Footwear Science 2011, 3:S13-S15.

doi:10.1186/1757-1146-5-S1-P28

Cite this article as: Thewlis et al:: Shoes that restrict

metatarsophalangeal dorsiflexion cause proximal joint compensations.

Journal of Foot and Ankle Research 2012 5(Suppl 1):P28.

\section{Submit your next manuscript to BioMed Central} and take full advantage of:

- Convenient online submission

- Thorough peer review

- No space constraints or color figure charges

- Immediate publication on acceptance

- Inclusion in PubMed, CAS, Scopus and Google Scholar

- Research which is freely available for redistribution

Submit your manuscript at www.biomedcentral.com/submit
C Biomed Central 